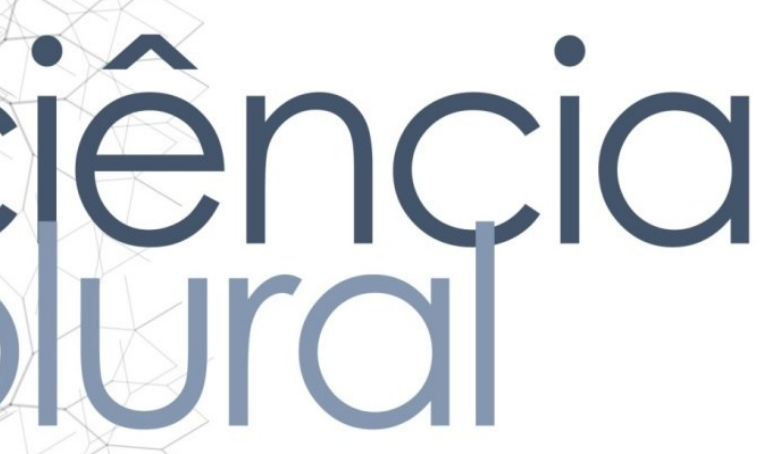

\title{
PERCEPÇÕES SOBRE OS EFEITOS PSICOSSOCIAIS DA GRAVIDEZ NA ADOLESCÊNCIA NO CENÁRIO DA ESTRATÉGIA SAÚDE DA FAMÍLIA
}

Perceptions on the psychosocial effects of pregnancy in adolescence in the scenario of the Family Health Strategy

Maísa Paulino Rodrigues • Doutora em Ciências da Saúde e Docente do Programa de Pós-Graduação em Saúde Coletiva (UFRN). E-mail: maisarodrigues13@gmail.com

Cláudia Maria Bezerra Varella do Nascimento - Médica da ESF Santarém (SMS-Natal/RN). E-mail: roselimamelo@hotmail.com

Ricardo Henrique Vieira de Melo • Dentista da ESF Nazaré (SMS-Natal/RN) e Mestre em Saúde da Família (RENASF/UFRN). E-mail: ricardohvm@hotmail.com

Dannielly Azevedo de Oliveira - Enfermeira e Docente (FACISA/UFRN). E-mail: danniellyazevedo3@gmail.com

Maria Ângela Fernandes Ferreira • Doutora em Odontologia e Docente do Programa de Pós-Graduação em Saúde Coletiva (UFRN). E-mail: angelaf50@gmail.com

Amanda Paulino de Oliveira - Enfermeira da Secretaria Municipal de Saúde (SMS-NN). E-mail: amandapaulinoo@hotmail.com

Autora responsável pela correspondência:

Maísa Paulino Rodrigues. E-mail: maisarodrigues13@gmail.com 


\section{RESUMO}

Introdução: A gravidez na adolescência representa um grave problema social e de saúde pública em muitos países do mundo. Objetivo: Identificar as percepções sobre os efeitos psicossociais da gravidez em adolescentes entre 14 e 19 anos, da área de abrangência da Unidade de Saúde da Família Santarém, que engravidaram ou se tornaram mães, no período de outubro de 2013 e dezembro de 2014. Métodos: Foi realizado um estudo descritivo, com abordagem qualitativa, junto a 22 adolescentes, sendo nove gestantes e treze mães, que representam $52 \%$ do total das adolescentes cadastradas na referida unidade. Para coleta do material foi utilizado um questionário semiestruturado. A análise dos dados foi feita pela técnica de análise temática de conteúdo. Resultados: Visualizamos os efeitos psicossociais negativos a partir do início da gravidez, ou seja, $82 \%$ das adolescentes não tinham a intenção de engravidar. Essa condição foi determinante para a interrupção dos estudos (45\%), com prejuízos na formação educacional e, consequentemente na capacitação profissional. Observou-se ainda que houve mudanças significativas na vida social, com restrições a liberdade e as opções de lazer, que foram substituídas pelos afazeres domésticos e cuidados com o filho. Aproximadamente $23 \%$ dos companheiros não assumiram a paternidade. Conclusões: Nessa perspectiva, espera-se que estes achados contribuam para um planejamento e melhor delineamento das ações de saúde na USF Santarém, tornando-as mais adequadas e eficazes para os adolescentes.

Palavras-chave: Gravidez na adolescência; Saúde da Família; Atenção Primária à Saúde.

\section{ABSTRACT}

Introduction: Adolescent pregnancy represents a serious social and public health problem in many countries of the world. Objective: To identify the perceptions about the psychosocial effects of pregnancy in adolescents between 14 and 19 years old, from the area covered by the Basic Health Unit of the Santarém Family who became pregnant or became mothers in the period of October 2013 and December 2014. Methods: A descriptive study with a qualitative approach was carried out with 22 adolescents, nine pregnant women and thirteen mothers, representing $52 \%$ of the total number of adolescents enrolled in this unit. A semi-structured questionnaire was used to collect the material. The analysis of the data was done by the thematic content analysis technique. Results: We visualized the negative psychosocial effects from the beginning of pregnancy, that is, $82 \%$ of the adolescents did not intend to become pregnant. This condition was determinant for the interruption of the studies (45\%), with losses in the educational formation and, consequently, in the professional qualification. It was also observed that there were significant changes in social life, with restrictions on freedom and leisure options, which were replaced by household chores and child care. Approximately $23 \%$ of the companions did not assume paternity. Conclusions: From this perspective, it is expected that these findings will contribute to a better planning and design of health actions at USF Santarém, making them more adequate and effective for adolescents.

Key words: Pregnancy in Adolescence; Family Health; Primary Health Care. 


\section{ciência plural}

\section{Introdução}

A adolescência corresponde ao período que sucede a infância e se prolonga por alguns anos, até a idade adulta. Este período, além da transitoriedade nos aspectos físicos e psicológicos, pode ser marcado por intensos conflitos na busca da autoafirmação, da formação da própria identidade, da separação progressiva dos pais. Caracteriza-se por ser um período de descoberta do mundo, dos grupos de amigos, de uma vida social mais ampla. Desta forma, cada vez mais, nos dias atuais, a saúde do adolescente é um tema oportuno, pertinente e relevante, que desperta interesse e proporciona o debate ${ }^{1}$.

A gravidez na adolescência representa um grave problema social e de saúde pública em muitos países do mundo. No Brasil esta realidade não é diferente e a literatura mostra que em um ano, de cada 100 mulheres que têm bebês, 28 têm menos de 18 anos de idade. Considerando que a população adolescente brasileira está estimada em aproximadamente $21 \%$ do total dos brasileiros, pode-se perceber a importância do problema para o país. Assim, essa gravidez pode interromper, na adolescente, o processo de desenvolvimento próprio da idade, fazendo-a assumir responsabilidades e papéis de adulta precocemente, já que dentro em pouco se verá obrigada a cuidar do seu filho².

Uma gravidez durante o adolescer representa uma questão de fundo psicossocial na medida em que reúne conflitos emocionais, psíquicos, sexuais, sociais e culturais. Reações como medo, insegurança, desespero, desorientação, solidão são muito comuns, principalmente no momento da descoberta da gestação. Ao engravidar, a jovem tem que enfrentar simultaneamente os processos de transformação próprios da adolescência e os provocados pela gestação, sofrendo uma intensa sobrecarga de esforços físicos e psicológicos que para suportá-la necessitaria apoiar-se num profundo desejo de tornar-se mãe. No entanto, na maioria das vezes não é o que acontece, as jovens se assustam quando são surpreendidas pela gestação, necessitando de cuidados médicos e materiais apropriados, de solidariedade humana e amparos afetivos especiais. Quanto ao jovem que se tornará pai, essa situação não é muito diferente, ele se vê tendo que lidar com as transformações próprias da adolescência e da paternidade, que exigem trabalho, estudo, educação do filho e cuidados com a esposa ou companheira 3 .

Para compreender os motivos que levam uma adolescente a engravidar, são necessárias muitas reflexões. Inclusivenão se pode ter uma falsa ideia de que toda gravidez seja inconsequente e desastrosa. É impossível ignorar que o problema é de difícil avaliação, pois se relaciona com o campo das sensações e emoções, onde o desejo de engravidar é muitas vezes inconsciente. A gravidez pode acontecer, tanto pela 


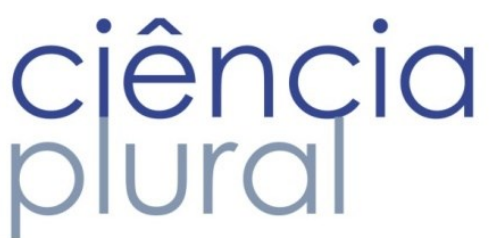

legítima vontade de querer ser mãe, quanto pela simples falta de informação sobre a sexualidade, saúde reprodutiva e métodos contraceptivos. Pode ainda estar relacionada com aspectos comportamentais, como a falta de habilidade da jovem em convencer ou até sugerir ao seu parceiro o uso do preservativo, ou ainda pela falta de noção quanto aos riscos a que se expõem não praticando sexo seguro 4 .

As ações de atenção à adolescente grávida exigem o conhecimento de suas condições de vida, do grupo social a que pertence, para compreensão de como vivenciam a gravidez precoce, que não se limita a um grupo social. Entretanto, na classe menos favorecida economicamente, há uma maior incidência devido às condições precárias de acesso às políticas públicas, o que irá refletir na forma de enfrentamento dessa gravidez. A continuidade dos estudos escolares, os estigmas sofridos pelos adolescentes, por sua família e pela sociedade, a relação com o pai da criança são questões a serem consideradas na condução de cada situação singular ${ }^{5}$.

A Unidade de Saúde da Família (USF) Santarém, situada na Zona Norte de Natal/RN, conta com quatro equipes de saúde da família responsáveis pela população residente em sua área de abrangência, cerca de 12.113 habitantes, perfazendo um total de 3.270 famílias. Entre estes, encontram-se 1.313 mulheres na faixa etária entre 10 e 19 anos.O atendimento na USF teve início em abril de 2002 e desde então, já no decorrer de alguns meses, observou-se um considerável número de adolescentes grávidas frequentando as consultas de pré-natal, levando grande preocupação às equipes de saúde.

De acordo com Gurgel et al ${ }^{6}$ trabalhar com os adolescentes é um grande desafio, pois este grupo etário quase não utiliza o serviço de saúde, e a falta de estrutura e recursos dificulta o processo de desenvolvimento de ações educativas voltadas à prevenção da gravidez na adolescência. As reflexões acerca desse tema se tornam relevantes para a Estratégia Saúde da Família, por ser porta de entrada dos usuários no Sistema Único de Saúde (SUS), para que se possa proporcionarao adolescente uma atenção acolhedora, ética, resolutiva e humana.

Autores 23,4 sugerem ainda uma priorização para a formação de grupos de adolescentes como espaço de valorização do autocuidado e da prática do sexo seguro e que a atenção ao adolescente seja por meio de uma abordagem interdisciplinar, com protocolo de atendimento, privilegiando as suas singularidades, na intençãodeampliaçãoda captação de adolescentes de ambos os sexos, estabelecendo parcerias na comunidade, dentre elas a escola, grupo de jovens, associação de moradores e entidades que realizem atividades esportiva.

Partimos do pressuposto de que o apoio dado à adolescente que engravida e ao seu parceiro não significa um estímulo à gravidez entre adolescentes, mas sim uma forma de criar condições para que esse 


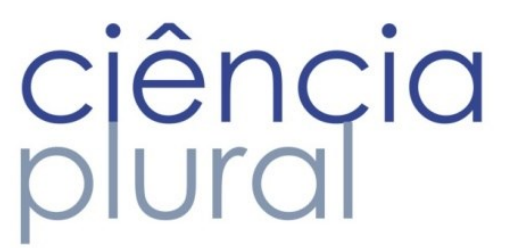

processo não resulte em problemas físicos e psicossociais, diminuindo assim suas graves consequências. Além disso, o quadro característico desenhado para essa situação contempla: uma gravidez geralmente inesperada, não planejada e com frequência indesejada, em mulheres solteiras, com baixa escolaridade, durante suas primeiras experiências sexuais, frequentemente sem proteção anticoncepcional (e para DST) e principalmente, em classes sociais mais pobres. Assim, a gravidez na adolescência pode representar uma limitação nas aspirações de seus projetos de vida e um comprometimento na qualificação destes jovens e dos seus filhos para o mercado de trabalho.

Dessa forma, o presente estudo tem por objetivo identificar as percepções sobre os efeitos psicossociais da gravidez em adolescentes entre 14 e 19 anos, da área de abrangência da USF do Santarém, tentando compreender as diferentes formas de vivenciar a gravidez e a maternidade a partir da subjetividade das adolescentes. Diante do exposto, faz-se necessário considerar as várias dimensões que perpassam pela vida das adolescentes grávidas, com vistas a ajudá-las a exercer a maternidade de modo a diminuir suas angústias incentivá-las à volta à escola, à reintegração no mercado de trabalho, a assumirem a responsabilidade pelas suas vidas, repensando suas escolhas, refazendo metas, além da orientação para prevenção de nova gravidez.

\section{Método}

A presente pesquisa trata-se de um recorte de uma investigação maior, de natureza qualitativa, por trabalhar com a dimensão do subjetivo e do simbólico das percepções, focando o processo vivenciado pelos sujeitos ${ }^{7}$.

Sobre os participantes da investigação, a USF do Santarém possuía em seu cadastro, no período do estudo, 42 adolescentes (gestantes e mães), assistidas pelas equipes de saúde. Destas, treze (13) eram gestantes e vinte e nove (29) já eram mães. Nesse universo, foram selecionadas, de forma aleatória, vinte e duas (22) adolescentes, na faixa etária entre 14 e 19 anos, compondo uma amostra formada por nove (9) gestantes e treze (13) mães. Estas adolescentes engravidaram ou se tornaram mães no período compreendido entre outubro de 2013 e dezembro de 2014.

As entrevistas individuais foram pensadas no intuito de caracterização dos sujeitos participantes e apreensão das percepções sobre o tema/problema investigado e foram realizadas na própria unidade de saúde em ambiente reservado e acolhedor. Os dados foram coletados entre os meses de junho a agosto de 


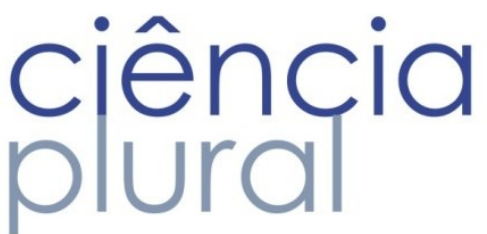

2014. O áudio das entrevistas individuais e das conversações nos grupos focais foi gravado em aparelho adequado (MP4) e, posteriormente, as falas foram transcritas para realização da análise.

Para análise os dados, fizemos opção pela técnica de Análise Temática de Conteúdo, sistematizada por Minayo $0^{8}$ pela pertinência para estudar motivações, atitudes, valores, crenças, tendências, caminhando na direção da descoberta do que está escondido por trás dos conteúdos manifestos, indo além das aparências do que está sendo dito. Compreendemos que o rigor da análise está na decomposição e recomposição simultâneas dos recortes de conteúdo (expressões, contradições, pausas, repetições) para melhor expressar sua significação em conjunto com as percepções do investigador na direção aos objetivos elencados na investigação.

Após a transcrição do material gravado, em uma fase de pré-análise, empreendemos uma leitura flutuante (preliminar e intuitiva) para compreensão do corpus de análise, formulação de pressupostos e leitura exaustiva dos conjuntos de textos sem intenção de perceber (naquele momento) elementos específicos. Finalmente, nesta etapa, ocorreu o tratamento e a interpretação dos resultados classificando os elementos segundo suas semelhanças e diferenças, categorização, inferência e reagrupamento. Desta forma a intenção foi desvendar o conteúdo latente, as tendências e as sínteses coincidentes e divergentes de ideias, através da reflexão e do confronto teórico com a realidade empírica.

$\mathrm{Na}$ fase de exploração fizemos a codificação a partir das Unidades de Registro (palavras, frases, parágrafos), e de Unidades de Contexto (temas, resumos, recortes de sentido, eixos, acontecimentos, respostas) buscando a transformação sistemática de dados brutos em núcleos de sentido.

No que diz respeito aos aspectos éticos, a investigação, devidamente aprovada no parecer de $\mathrm{n}^{0}$ 440.324, em 27/09/2013, pelo Comitê de Ética em Pesquisa (CAAE: 17773213.7.0000.5292), seguiu as diretrizes e normas regulamentadoras para pesquisa envolvendo seres humanos ${ }^{9}$, aprovadas pelo Conselho Nacional de Saúde do Ministério da Saúde, conforme resolução $n^{0} 466 / 12$, no que se refere às suas recomendações, tais como: esclarecimentos necessários a todos os integrantes, participação voluntária, assinatura do termo de consentimento livre e esclarecido, sigilo e guarda das informações, entre outras. Os custos do projeto foram mínimos e relacionados apenas a materiais de expediente e alguns serviços de terceiros, a serem assumidos pelo próprio pesquisador.

Os riscos foram mínimos e estiveram apenas relacionados a algum constrangimento nas entrevistas individuais e/ou coletivas, ao relatar situações vivenciadas. Foram resguardadas as identidades dos participantes e o sigilo das informações. Com vistas a manter o sigilo sobre a identidade das entrevistadas, optou-se por colocar pseudônimo de flores, seguido da idade. 


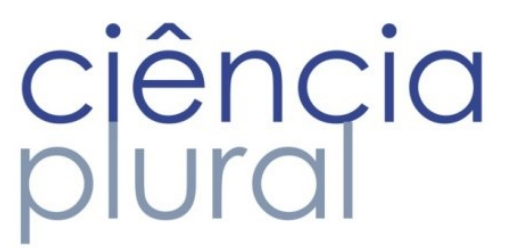

Na ocasião os sujeitos foram esclarecidos sobre a pesquisa em aspectos que julgaram necessidade, e ficaram livres para a retirada do consentimento ou interrupção da participação a qualquer momento e em qualquer fase da pesquisa.

\section{Resultados e discussão}

A gravidez na adolescência certamente acarreta grandes modificações psicológicas, emocionais e sociais, e os resultados, muitas vezes, são contraditórios e representam as ambivalências e as contradições próprias da adolescência retratando a complexidade da maternidade nessa etapa de desenvolvimento. $\mathrm{A}$ nova realidade apresentada pelo nascimento do bebê se dá de forma impactante, modificando intensamente os projetos de vida de cada adolescente ${ }^{10}$.

\section{O perfil das adolescentes grávidas}

Na faixa etária observada (entre 14 e 19 anos), 18\% das adolescentes tinham 14 anos de idade ao se descobrirem grávidas. Esse número pode ser considerado significativo enquanto fenômeno de natureza social. Cerca de $64 \%$ dos companheiros dessas adolescentes estavam na faixa etária entre 20 e 34 anos, onde $77 \%$ deles estavamdesempregados, e a renda mensal de $36 \%$ deles girava em torno de um a três salários mínimos. As outras adolescentes desconheciam a renda de seus companheiros. Isso demonstra que, apesar da convivência e da intimidade do casal, as jovens não têm acesso, ou não dão importância a esta informação.

De acordo com as respostas coletadas, $23 \%$ das adolescentes estavam desempregadas, mostrando a magnitude do problema, ficando as despesas financeiras a cargo dos familiares de um deles. Sabe-se que a dificuldade econômica, a responsabilidade precocemente assumida e outras dificuldades do cotidiano são fatores que provocam desentendimentos e desgastes da relação, concorrendo para a separação do casal.

A situação conjugal que predominou foram uniões estáveis (54\%). Aquelas adolescentes que permaneceram solteiras, representando $23 \%$ do total, relataram que viviam em relacionamentos casuaise sem compromissos mais sérios, inclusive assumindo os cuidados e as despesas com o filho, visto que os companheiros não assumiram a paternidade, tampouco demonstraram interesse em uma relação estável. Das adolescentes participantes, $32 \%$ residiam com seus companheiros, $32 \%$ moravam com o companheiro e familiares, e o restante, $36 \%$, residiam com seus familiares, sem o companheiro. 


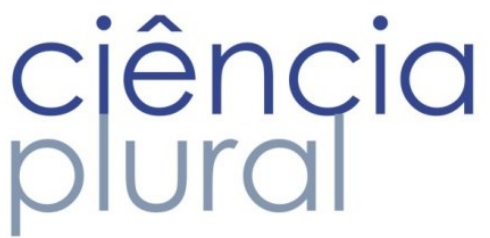

Segundo Castro e Pereira ${ }^{10}$, as chances das mulheres de 15 a 19 anos iniciar e manter uma união surgem em decorrência do nascimento de filhos, pressionando a constituição dessas uniões. Essa pressão, entretanto, cria laços frágeis e suscetíveis à dissolução, o que, a longo prazo, do ponto de vista econômico e educacional, se constitui em desvantagem para as mulheres. 0 fato de o casal permanecer na casa dos pais ou de familiares de um deles, na maioria dos casos (68\%), indica que a renda do jovem pai não é suficiente para sustentar uma casa e a nova família, ou até mesmo por não se sentirem psicologicamente preparados para tal experiência, obrigando-os a viver sob o mesmo teto com suas famílias. Dessa forma, essas famílias têm que dividir a casa e o orçamento, já limitados, não sendo suficientes para suprir a todas as necessidades.

A introdução de um novo membro no grupo familiar quebra a estrutura de funcionamento, exigindo uma reorganização do espaço e das relações. Cabe ressaltar que as famílias dessas adolescentes, $64 \%$, parecem ter reagido naturalmente, aceitando a gravidez, acolhendo a filha.

Foi possivel observar que todas as adolescentes têm mais de quatro anos de estudo. Na verdade, $64 \%$ delas estudaram por mais de sete anos, contrariando, de certa forma, o senso comum que relaciona 0 baixo nível educacional a uma maior fecundidade. Nessa perspectiva, esperava-se que um melhor nivel de escolaridade se refletisse, também, em uma melhor compreensão a respeito dos riscos das doenças sexualmente transmissíveis e da gravidez precoce. Entretanto, isso não se confirmou nos resultados encontrados.

Constatou-se que $36 \%$ das adolescentes cursam ou cursavam o ensino médio e $64 \%$ o ensino fundamental. De acordo com as entrevistas a intenção da maioria era permanecer estudando, e aquelas que interromperam os estudos, demonstraram o interesse em retomá-los tão logo seja possível. É difícil acreditar que essas adolescentes consigam manter as atividades escolares, ao mesmo tempo em que assumem as funções de mãe e de dona de casa. Entretanto o apoio familiar é imprescindível para que essas adolescentes possam de fato continuar seus estudos.

A representação social das mães adolescentes em relação à gestação, em sua maioria, se dá por uma idealização da maternidade e do amadurecimento como mulher, do qual acarretam sentimentos ambivalentes, confrontando os desejos de ser mãe, socialmente reconhecida, com as reais necessidades do bebê e as dificuldades encontradas na maternidade ${ }^{10}$.

Apesar de grande parte da literatura $4,5,6$, considerar a gravidez na adolescência como um risco, as características reprodutivas das mães adolescentes demonstram que, $92 \%$ estavam sendo mães pela 


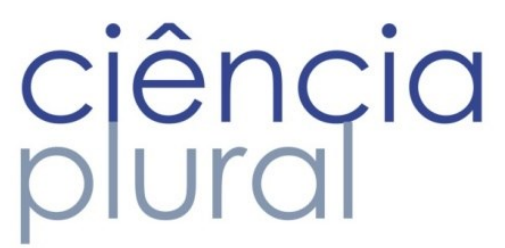

primeira vez, parindo seus filhos através de parto normal, sem complicações e com peso igual ou maior que 2.500g.

\section{As atitudes frente à gravidez}

$\mathrm{O}$ acesso aos métodos contraceptivos e ao planejamento familiar faz parte da carteira de serviços das Unidades de Saúde da Família, mas as adolescentes procuram pouco. É real a necessidade de programas educativos mais eficientes envolvendo os adolescentes no ambiente escolar, família e na ESF, uma interdisciplinaridade entre saúde e educação, capaz de enfrentar os desafios da orientação sexual para adolescentes.

Reforça-se a importância de investimentos na educação sexual dos adolescentes, e que as equipes de saúde permaneçam vigilantesquanto ao desenvolvimento de ações na promoção, reflexão e conscientização dos adolescentes em relação às questões da anticoncepção, na intenção de disparo de mudanças de comportamento e do respeito, eda capacidade individual em receber e processar as informações para utilizá-las corretamente ${ }^{11}$.

Em relação à contracepção, $73 \%$ das adolescentes afirmaram o uso de algum método contraceptivo antes de engravidar. Percebe-se uma contradição entre o dizer e o fazer dessas jovens, visto que todas engravidaram. Isso pode significar que o uso do contraceptivo estava sendo feito de forma incorreta ou que existia o desejo inconsciente de se tornarem mães. Desse universo, a metade (50\%) referiu que o parceiro fazia uso de preservativos, sendo que $9,1 \%$ delas faziam uso de anticoncepcional oral, $9,1 \%$ usavam anticoncepcional injetável, e 4,5\% referiu que fazia tabela há cerca de sete anos, o que chamou à atenção, visto que, durante a entrevista esta adolescente afirmou que antes de engravidar, era garota de programa.

Os achados deixam evidente a pouca importância que essas adolescentes atribuem a contracepção, como se vida sexual ativa sem proteção não fosse sinônimo de gravidez e de adoecimento por doenças sexualmente transmissíveis, ou até mesmo, que uma gravidez inesperada não represente impedimento para suas vidas. Sabe-se que no Brasil, a contracepção na adolescência é praticada de modo deficiente. Restrições de ordem familiar e social impedem as adolescentes de procurarem recursos contraceptivos. Consequentemente, o que se observa é que a maioria das adolescentes inicia sua vida sexual sem nenhuma orientação contraceptiva. Ademais, quase todos os programas de planejamento familiar contemplam mais as mulheres adultas, não prevendo também, 0 atendimento das adolescentes.

No referente à intenção de engravidar, as respostas mostram que apenas 18\% das adolescentes referiram que a gravidez foi planejada.Percebe-se certa relação entre o número de adolescentes que não 
tinham intenção de engravidar (82\%) e aquelas que referiram o uso de método contraceptivo antes da gravidez (73\%). Entretanto, talvez o método tenha sido empregado de forma errônea ou haja um desejo latente de ser mãe.

Para compreender tal contradição (desejo de não engravidar versus uso de contraceptivos) podese levantar a ideia do senso comum, onde o papel de mãe é amplamente valorizado e desejado, e a crença de que uma gravidez mesmo que inesperada possa se transformar em uma história de amor, abençoada com um filho e com final feliz, como nos contos de fadas. A falta de informação, e o despreparo desses jovens para a vida sexual, são reflexos da exclusão dos processos de comunicação, e ain da, da exclusão dos espaços institucionais (socioculturais).

\section{0 apoio recebido}

Sabe-se que a gravidez não planejada leva frequentemente ao aborto, e que apesar da ilegalidade, quando realizado em condições precárias, pode causar a esterilidade e até a morte da jovem. Assim, $27 \%$ das adolescentes pensaram em abortar, no entanto, apenas uma referiu ter chegado a tomar chás com esta intenção. O fato de $27 \%$ das adolescentes "pensar" em abortar sem, entretanto, tomar alguma iniciativa, pode significar que elas contavam com o apoio/aceitação do companheiro, da família, ou de ambos, para levar a termo a gravidez. Este apoio certamente deve ter sido importante para ajudá-las a enfrentar seus medos, suas angústias e a gravidez de forma mais tranquila. Entre estas, algumas relataram não ter recebido apoio do companheiro e/ou da família, mas nem por isso provocaram o abortamento.Ao serem questionadas sobre o apoio recebido do companheiro, elas se expressaram da seguinte forma:

"Ele falou de bater ultra para saber o que é". (Margarida, 16 anos).

"Ele deu muito apoio. Ficou comigo, montou casa". (Rosa, 16 anos).

"Ajuda muito. Não vive brigando". (Bromélia, 14 anos).

"Deu todo apoio. Acompanhando e visitando no hospital". (Orquídea, 17 anos).

"Sim, ficou animado, comprava as coisas para a filha". (Jasmim, 14 anos).

"Sim, logo no início, depois ele se desligou mais". (Flor do Campo, 18 anos).

"Sim, procurou me acalmar dizendo que arcaria com a responsabilidade da parte dele". (Angélica, 18 anos).

Ao serem questionadas a respeito do apoio do companheiro em relação à gravidez, a maioria respondeu que $\operatorname{sim}(73 \%)$, mas através de uma leitura mais profunda das falas, percebe-se que o "apoio recebido" se refere em grande proporção às questões de infra-estrutura, para viabilizar a subsistência, não apresentando um sentido mais abrangente, ou seja, de afeto, de companheirismo, de cuidado, de 


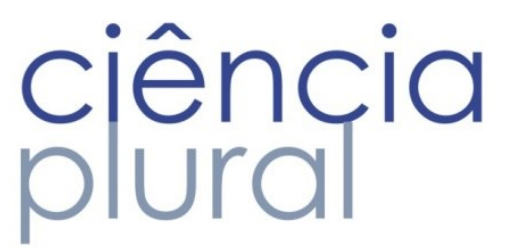

participação, de responsabilidade, de solidariedade, e não apenas de compensação material. Em relação ao apoio recebido da família, as adolescentes se expressaram da seguinte forma:

"No começo houve dificuldades para aceitarem a gravidez". (Violeta, 16 anos).

"Não me sinto feliz na minha família. A gente não se entende muito bem". (Cravo, 15 anos).

"No início foi difícil, agora está bem". (Papoula, 17 anos).

"A minha mãe não queria". (Girassol, 14 anos).

"O meu pai ficou magoado". (Orquídea, 17 anos).

Essas falas traduzem um pouco da dificuldade que algumas famílias têm em aceitar a gravidez precoce, não planejada, de suas filhas. Após o choque inicial provocado pela descoberta da gravidez, 64\% das famílias souberam acolher e apoiar suas filhas. Estes achados estão em concordância com a opinião de Costa et al ${ }^{12}$ ao referirem que a família age como uma peça fundamental no sistema de solidariedade social, sendo capaz de modificar sua estrutura e absorver novos membros, inclusive uma outra família, que se agrega na forma de uma extensão familiar residindo no mesmo domicílio e compartilhando de outros recursos da família principal.

Alguns autores ${ }^{3,5,8}$ apontam que 0 acolhimento e 0 cuidado continuado adequado prestado à adolescente, pela ESF, a partir da descoberta da gravidez, representa um apoio de grande valia, nos momentos iniciais de negação por parte da jovem grávida e atuando de maneira a evitar outros problemas, tais como o aborto e/ou o isolamento social. Esse suporte geralmente cabe à própria família e, muitas vezes, à escola, de informar e incluir, ao invés de segregar e marginalizar. Os profissionais da atenção primária têmainda o papel de promover a emancipação, não do indivíduo por si mesmo, mas também da família, na criação de vínculos duradouros, na segurança emocional, durante o período de maior vulnerabilidade ${ }^{12}$.

\section{A percepção da gravidez}

Quando abordadas sobre o sentimento em relação à gravidez, metade das adolescentes apontou para o aumento da responsabilidade como o principal sentimento provocado por uma gravidez. Algumas se referiram à gravidez como algo bom (14\%), entretanto, outras consideraram que a gravidez era ruim (9\%) euma boa parcela (27\%), associou a gravidez à realização pessoal e a felicidade.

Muitas vezes a impressão que se tem é que essas adolescentes não veem à ocorrência de uma gravidez precoce como uma questão difícil e problemática, elas encaram com naturalidade todas as mudanças que vão se impondo, sejam elas corporais, sejam no contexto familiar e social. Foi possível verificar que em certas falas elas se mostram animadas com a perspectiva da maternidade, entretanto, 


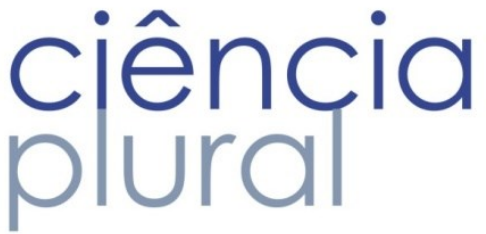

através de outras foi possível captar um certo peso, uma sobrecarga, estresse e insatisfação, como se pode observar a seguir:

"Preocupada, porque foi inesperada". (Azaléia, 19 anos).

"Presa. É muita responsabilidade". (Lírio, 18 anos).

"É chato porque já tenho uma menina". (Rosa, 16 anos).

"Não quero outra filha". (Begônia, 17 anos).

"No início não aceitava, não quero nunca mais". (Crisântemo, 17 anos).

"Sentia-me muito ruim. Pensei que o mundo tinha acabado". (Dália, 18 anos).

Pode-se notar que o sentimento em relação à maternidade é positivo na maioria das respostas uma vez que $62 \%$ mostram satisfação. Estas mães mostraram-se confiantes, felizes, realizadas, assumindo 0 papel socialmente esperado de mãe orgulhosa do filho, responsável, cuidadosa e de adulta. A vida é dedicada exclusivamente ao filho, este passa a ser o centro do seu universo e de sua atenção.

"É bom ser mãe pela primeira vez" (Antúrio, 19 anos).

"A mãe mais feliz do mundo". (Begônia, 17 anos).

"Feliz, porque era um sonho". (Gladíolo, 19 anos).

"É ótimo, sou louca pelo meu filho". (Orquídea, 17 anos).

"Ótima, gosto muito de cuidar dela, é uma companhia constante". (Acácia, 14 anos).

"Feliz, achava que ia ser mais difícil, por enquanto está tranquilo". (Angélica, 18 anos).

\section{Os aspectos negativos da gravidez}

As adolescentes grávidas manifestam frequentemente uma percepção negativa frente à gestação, seja por não ter sido planejada ou por ter interrompido ou postergado seus projetos pessoais, pela frustração e medo e por não gostar do novo corpo. Para minimizar esses aspectos negativos, o atendimento ao adolescente pede dedicação, disponibilidade e criatividade do profissional da saúde. Os serviços de saúde devem ser acessíveis, acolhedores resolutivos e competentes para apreender a atenção dos adolescentes, principalmente nas atividades coletivas e nos programas de orientação sexual, onde a conversa pode potencializar melhores resultados, em termos de adesão às medidas de proteção e de prevenção de gravidez precoce ${ }^{13}$.

Apenas uma adolescente referiu uma melhoria no relacionamento com o companheiro.Os dados mostram que os casais se relacionavam há algum tempo (59\%), quando ocorreu a gravidez. Enquanto $36 \%$ dos casais passaram a morar junto após a gravidez, e $23 \%$ já dividiam o mesmo teto. As adolescentes que 


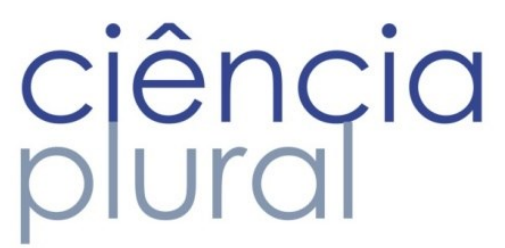

já mantinham uma união estavam sendo mães pela segunda vez. Em $18 \%$ dos casos os companheiros não assumiram o filho, entretanto, estas adolescentes encontraram um outro namorado que, de acordo com elas, estavam inclinados a criar o seu filho.

"Melhorou o relacionamento com o meu marido" (Tulipa, 19 anos).

"É outro, sem ser o pai do bebê". (Miosótis, 18 anos).

"A gente se dá muito bem, mas briga muito". (Lírio, 18 anos).

"Vivo bem, não sou das piores". (Rosa, 16 anos).

"Primeiro namorado, já vivia com ele há um ano". (Violeta, 16 anos).

"Não quero mais ele. Ele só quer viver do lado errado". (Crisântemo, 17 anos).

"É complicada porque ele gosta de beber e temos que viver com a família dele". (Girassol, 14 anos).

"Não está muito legal. Temos discutido muito". (Flor do Campo, 18 anos).

"A gente já namorava há três anos e pensava em casar". (Angélica, 18 anos).

De acordo com os resultados $64 \%$ das adolescentes referiram mudanças de comportamento em relação as suas vidas sociais, $36 \%$, afirmou que não tinham o costume de sair com frequência, de ir a festas, andar em turmas, afirmando que a gravidez não interferiu nas atividades sociais. Entretanto, pode-se observar que houve mudanças na vida social através das falas seguintes:

"Tinha uma vida social mais tumultuada, saía mais, bebia". (Azaléia, 19 anos).

"Antes só queria viver de curtição". (Lírio, 18 anos).

"Vivia em festas, saía muito. Fez a juventude passar muito rápido". (Rosa, 16 anos).

"A vida era boa. Não tenho ido a festas, só vivo dentro de casa". (Cravo, 15 anos).

"Vivia na rua, fazia programa. Agora não saio de casa". (Begônia, 17 anos).

A análise permitiu averiguar que $55 \%$ das adolescentes permanecem estudando, $27 \%$ referiu ter abandonado os estudos a partir da gravidez, enquanto que $18 \%$ o fez por outros motivos, quais sejam: conclusão do ensino médio, trabalho de doméstica, perda do interesse pelos estudos e a ausência de vaga na escola. Analisando estes dados, constata-se que $45 \%$ das adolescentes interromperam os estudos, confirmando que a maternidade reduz a frequência das mulheres à escola, seja porque as pressiona a assumir responsabilidades com casa e filho, ou porque o modelo de escola não é preparado para receber as jovens com filhos.

Observa-se um número elevado de jovens que adiam seus projetos de estudo para o futuro, mas, quando se trata de população de baixa renda, onde geralmente o ensino não é de qualidade, e a escola não parece atraente e estimulante e, estudar exige muita determinação e esforço, essa condição de gravidez 


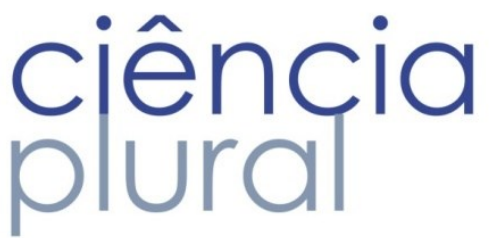

traz ainda mais dificuldades. Nos casos onde as adolescentes referiram ter interrompido os estudos por outros motivos, é possivel que a gestação tenha sido a principal causa, entretanto negada pelas jovens, visto que há uma pressão da sociedade no sentido da formação educacional formal, como condição para o ingresso no mercado de trabalho.Alguns discursos refletem o sentimento de perda e a tristeza por terem interrompido os estudos.

"É ruim porque aprende menos". (Rosa, 16 anos).

"Revoltada, porque parei de estudar". (Cravo, 15 anos).

"Antes não ligava, agora me sinto mal". (Crisântemo, 17 anos).

"Atrapalhou apenas o estudo, mas lá pra frente pretendo retomar". (Papoula, 17 anos).

No grupo das adolescentes entrevistadas, apenas uma se encontrava trabalhando, $27 \%$ haviam trabalhado anteriormente, mas na ocasião da entrevista estavam desempregadas. Entre aquelas que trabalhavam (27\%), dois terços relataram ter parado de trabalhar por haver engravidado e um terço afirmou que 0 trabalho estava prejudicando os estudos. Quando questionadas sobre 0 sentimento em relação ao trabalho, obteve-se as seguintes respostas:

"Depois que engravidei tive que parar de trabalhar. Preconceito que o povo tem com a gravidez". (Papoula, 15 anos).

"Não posso trabalhar porque não terminei os estudos. Tenho que cuidar da casa e do filho". (Girassol, 14 anos).

"Antes estudava, trabalhava, tinha apoio da família, que hoje não tenho". (Miosótis, 15 anos).

"Adiei alguns planos, mas trabalhava, saía, ia a festas". (Angélica, 18 anos).

"É muito ruim a pessoa parada". (Antúrio, 19 anos).

São vários os aspectos que influenciam o aumento da gravidez na adolescência: a mídia e os meios de comunicação; a quebra de tabus na modernidade; adesinibição sexual; a dificuldade de diálogo; a desestruturação familiar; o distanciamento da escola, a menarca cada vez mais precoce; a necessidade de autoafirmação e 0 ritual de passagem para a idade adulta.

Torna-se relevante levar em consideração a elaboração de propostas de enfrentamento desta problemática por todos os segmentosda sociedade com a finalidade de mitigar as repercussões psicossociais encontradas na maioria das adolescentes grávidas, tais como: Abandono temporário ou definitivo da escola pela falta de estrutura para estudar e criar o filho; perda da confiança na família; maior empobrecimento familiar quando com baixa renda ao assumir a filha grávida; estigma e pressão social na família e na comunidade;vergonha ou medo das relações sociais entre os pares;maiores ocorrências de 


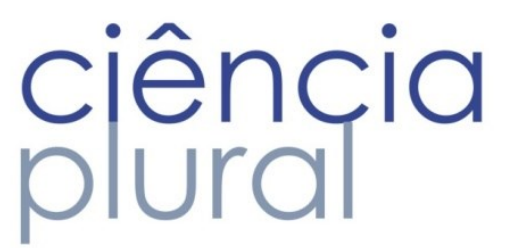

ansiedades, angústias e dúvidas;casamentos não planejados; condições de moradia precárias; altas taxas de separações, uma vez que uniões antes dos 20 anos de idade têm um desfecho infeliz em três a quatro vezes mais que as contraídas após os 20 anos de idade $14,15,16$.

\section{Considerações finais}

O estudo caracterizou o perfil das adolescentes grávidas adscritas à USF Santarém e as diferentes percepções sobre as experiências vividas por elas. Percebe-se que essas jovens, ao se tornarem mães, perderam a liberdade, mudando sobremaneira a vida social a partir da gravidez. Seus projetos de vida foram adiados para o futuro, pelo abandono da escola, limitando assim as perspectivas de capacitação profissional e ingresso no mercado de trabalho. Muitas não tiveram nem a oportunidade do primeiro emprego, enquanto aquelas que trabalhavam, foram pressionadas a parar para cuidar do filho.

Assim, quando a educação sexual dos filhos for assumida de forma efetiva pelos pais e educadores, possivelmente a ocorrência de gravidez na adolescência venha a diminuir, uma vez que, eliminar tal problema é quase impossível, dada à complexidade das questões psíquicas e sociais que envolvem esta temática. É importante conhecer de maneira mais profunda, através de investigações adicionais, a realidade da gravidez na adolescência em cada contexto social e territorial.

Permanecem questionamentos complexos que merecem atenção especial necessitando de uma melhor compreensão, como por exemplo, a associação existente entre a situação de pobreza, baixa escolaridade, abandono escolar, perda de emprego, uniões instáveis, mudanças nos planos de vida e gravidez em idade precoce. Faz-se necessário compreender que lugar os adolescentes do sexo masculino ocupam nesse cenário, se assumem a paternidade, se as famílias envolvidas apoiam a gravidez/paternidade de seus filhos.

Estes e outros aspectos podem ampliar o conhecimento vigente para servir de ponto de partida que torne possível desenhar propostas efetivas e adequadas de intervenção para essa clientela. Nessa perspectiva, espera-se que os achados deste estudo possam contribuir para um planejamento e melhor delineamento das ações de saúde na USF Santarém e nos espaços de contextos semelhantes, tornandoas mais adequadas e eficazes para os adolescentes. 


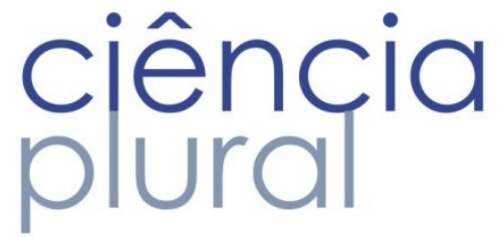

\section{Referências}

1. Ribeiro VCS, Nogueira DL, Assunção RS, Silva FMRS, Quadros KAN. O papel do enfermeiro da estratégia de saúde da família na prevenção da gravidez na adolescência. Rev. Enferm. Cent. O. Min. 2016 jan/abr;1(6):1957-1975.

2. Fonseca FF, Sena RKR, Santos RLA, Dias OV, Costa SM. As vulnerabilidades na infância e adolescência e as políticas públicas brasileiras de intervenção. Rev. Paul. pediatr. 2013 Jun;31(2):258264.

3. Schwanke M, Pinto AB. A percepção dos adolescentes residentes no município de alto bela vista - SC sobre a gravidez na adolescência. Ágora Rev Divulg Cient. 2012;16(2 Esp):150-160.

4. Santos AAG. Sentidos atribuídos por profissionais à promoção da saúde do adolescente. Ciênc Saúde Coletiva. 2012;17(5):1275-1284.

5. Squizatto EPS, Herculano LRF. Gravidez na adolescência e o serviço social. Rev Saber Acad. 2013;(16):14-22.

6. Gurgel MGI, Alves MDS, Moura ERF, Pinheiro PNC, Araújo MAL, Rêgo RMV. Ambiente favorável à saúde: concepções e práticas da enfermeira na prevenção da gravidez na adolescência. Rev. Rene. 2010; 11(Esp):82-9.

7. Deslandes SF, Gomes R. Pesquisa social: teoria, método e criatividade. Petrópolis: Vozes; 2012.

8. Minayo MCS. O desafio do conhecimento: pesquisa qualitativa em saúde. 14ed. São Paulo: Hucitec; 2014.

9. Brasil. Ministério da Saúde. Resolução CNS/MS n 466, de 12 de dezembro de 2012. [internet].Disponível em:http://bvsms.saude.gov.br/bvs/saudelegis/cns/2013/res0466_12_12_2012.html

10. Castro ASVP; Pereira BS. Representação social de adolescentes frente à gravidez. Rev Psique. 2016; 1(1):86-101.

11. Silva MRB, Silva LA, Maturana HCA, Silva RB, Santos ME, Filho VF. Porque elas não usam?: um estudo sobre a não adesão das adolescentes ao preservativo e suas repercussões. Saúde em Redes. 2015;1 (4):75-83.

12. Costa TLA, Carvalho NAR, Santos JDM, Silva BJC, Moura MMM. Gravidez na adolescência: contribuição dos serviços ofertados por uma instituição filantrópica. Rev Interd. 2016 abr/mai/jun; 9(2):160-167. 
13. Rodrigues ARS, Barros WM, Soares PDFL. Reincidência da gravidez na adolescência: percepções das adolescentes. Enferm. Foco. 2016; 7(3/4):66-70.

14. Davim RMB, Davim MVC. Estudo reflexivo sobre aspectos biológicos, psicossociais e atendimento pré-natal durante a gravidez na adolescência. Rev enferm UFPE. 2016; ago 10(8):3108-3018.

15. Wildemberg FM, Araújo A, Caetano de Souza, Christina M. A prevenção da gravidez na adolescência na visão de adolescentes. Texto \& Contexto Enferm 2015; 24(1)30-37.

16. Guanabens MFG; Gomes AM, Mata ME, Reis, ZSN. Gravidez na adolescência: um desafio à promoção da saúde integral do adolescente. Revista Brasileira de Educação Médica. 2012; 36(1, Suppl. 2), 20-24. 